\title{
Sustainability of E-learning in Vietnam: The case study of FPT University
}

\author{
Vu Minh Trang \\ FPT University, Hanoi, VIETNAM
}

\section{ABSTRACT}

This paper aims to analyze the sustainability of E-learning of the university education system in Vietnam, specifically FPT University, during the Covid 19 epidemic. In the case of FPT University in this research, the students and teachers and managers from the Business Administration department, who are already familiar with online learning methods, gave information about their perspectives about the sustainability of E-learning based on Environmental, Economic and Social aspects. Furthermore, the lecturers, students, and managers concluded the best sustainable learning method among Synchronous Asynchronous, and Blended Learning. Moreover, some recommendations to sustain E-learning are proposed to strengthen the E-learning system in Vietnam. Qualitative research is applied in this study to find out the sustainability of E-learning in Vietnam.

Keywords: Sustainability, E-learning, online learning

\section{INTRODUCTION}

Online learning is picking up ubiquity worldwide, lessening the worldly and spatial issues related to the conventional frame of instruction. The exponential development of the Web has empowered people to share data, take an interest, and collaborate to memorize from virtual 
communities (VC) anytime and anyplace (Rennie \& Morrison 2013). The development of the e-learning showcase can be illustrated by the reality that the worldwide e-learning advertisement is anticipated to reach 65.41 billion dollars by 2023, developing at a cumulative average development rate of $7.07 \%$ (Research and Markets 2018). Currently, students can learn by three online learning methods: (1) asynchronous learning, (2) synchronous learning, and (3) blended learning (combination of face-to-face and pure online learning) (Kim \& Bonk 2006, p. 25).

Online learning is a new and booming industry in Vietnam that finds its way to many people and is the current trend in education. Vietnam is currently one of the ten markets with the highest growth rate in elearning, which is $44.3 \%$ in 2018 , and according to research conducted by Ambient Insight (2021), the value of a global tech company that specified in education startups is estimated at more than 190 billion US dollars in 2018 then is expected to exceed 300 billion by 2025 (Le 2019). As one of the most prioritized businesses in Vietnam, the education business is heavily invested in by companies and expanding quickly. Vietnam's most significant online learning community is hocmai. vn, with nearly 300 teachers and professors helping close to 4 million registered members, and is the home of many valedictorians and scholars (Hocmai 2020). Different countries have different reasons to invest in E-learning; some think of it as a way for developing countries to catch up to developed countries by closing the knowledge gap by learning from foreign teachers through online learning. Vietnam is also a potential market for investors to rest in and boost the national GDP. E-learning is placed among "the rise in skills, services, digital businesses, and the free employment economy" trend group that promotes Vietnam's digital economy. Online learning and self-learning trends are appreciated for development (Dan 2019). Amid the Corona epidemic that is happening worldwide, Vietnam has decided to temporarily close down schools and other educational institutes to minimize the rate at which the virus spread. This decision has proven to be controversial, with many agreeing with the government while others don't want to be restricted. The Ministry of Education and Training and several schools, including FPT University, decided to let 
students continue their classes by e-learning as a safe way for students to continue their curriculum while avoiding unnecessary danger from going outside.

However, Online Learning is concerned about sustainability after Covid in Vietnam (Brundtland \& Khalid, 1987; Castells, 2001). From the perspective of Mr. Nguyen Thanh Nam, Head of FUNIX, which the first online university that belongs to FPT Cooperation in Vietnam, there is high potential for sustainable development of online learning in the future. Therefore, the research is conducted in this technologyleading university to discover student-centred online education sustainability in Vietnam. All students and lecturers are forced to apply online learning during the Covid time.

FPT University is a private university founded on September 8, 2006, and was funded entirely by the FPT corporation making it the first higher education institution in Vietnam established by a business. FU has always been well-known for education innovation and is one of the leading institutes offering a wide range of online learning systems:

(1) asynchronous learning: through recorded videos on Massive Open Online Courses (MOOC) or Learning Management system (LMS)

(2) synchronous learning: through live video conferencing on Google Meet, Zoom etc.

(3) blended learning (a combination of face-to-face and pure online learning.

Therefore, three research questions are proposed as follow:

1. How do the students/teachers/managers perceive the probability of sustainability of E-learning in University based on Social, Environmental, and Economic aspects?

2. What are the challenges for the sustainability of E-learning?

3. Which method is the best method for sustainability of E-learning in University: asynchronous, synchronous, or blended learning? Why? 
Data was collected through individual online interviews with Business Administration managers, lecturers and students of FPT University from 28th February 2020 to 28th May 2021.

\section{LITERATURE REVIEW}

\subsection{Definitions}

\subsubsection{Online learning/ E-learning}

E-learning or online learning is a term that has attracted the attention and attention of many people today. However, there are many different definitions of this term.

According to Dan (2020), E-learning is all students training towards achieving learning goals, including direct interaction between the teacher and the learner, such as between the community learning smoothly through information technology and tradition. In this model, teachers will try to build electronic lessons in the most straightforward way to replace teachers to interact with learners through the Internet and computer screens.

According to Singh and Thurman (2019), Online learning or E-learning is characterized as an instrument that can make the teaching-learning preparation more student-centered, inventive, and adaptable. Online learning is described as "learning encounters in synchronous or nonconcurrent situations utilizing various gadgets (e.g., portable phones, tablets, etc.) with web access. In these situations, understudies can be anyplace (free) to memorize and connect with teachers and other students".

Synchronous learning is organized within the sense that understudies go to live addresses, there are real-time interactions between educators and learners, and moment criticism is plausible. Synchronous learning can give a lot of openings for social interaction (McBrien et al., 2009). Amid the spread of this fatal virus, such online platforms as (a) video conferencing with at least 40 to 50 students, (b) 
discussions with students to keep classes organic, (c) good internet connections, (d) lectures are accessible in mobile phones as well as laptops, (e) the ability to watch previously recorded lectures, and (f) instant feedback from st (Basilaia et al., 2020).

Asynchronous learning is not legitimately structured. Learning content is not available in live lectures or courses in such a learning environment; instead, it is available through various learning systems and forums. In such a setting, instant feedback and immediate response are not conceivable (Littlefield, 2018).

\subsubsection{Sustainability}

In recent years, sustainable development has become an indispensable global trend. Universities are faced with challenges in joint sustainable development, including economic, social, educational and environmental issues, the introduction of cooperation strategies, action-oriented, ambitious strategies. Therefore, addressing these issues is utterly necessary for universities to sustain the number of students participating in studying online in the future.

A system is said to be sustainable if it meets the requirements for sustainability, consisting of a beneficial and harmonious combination of the following aspects: Human, social, technical, environmental and economic (Alharthi, Spichkova \& Hamilton 2019). One dimension of sustainability cannot be consolidated without connecting the other dimensions. Although sustainability has been considered from philosophical, historical, economic, political, social, and cultural perspectives (Stepanyan et al., 2013), it is usually more closely associated with environmental science, social and economics. Thus, sustainability is inclusive: "green" software systems mean reduced energy consumption and resource waste in processes, and the context of "green software systems" includes human and economic sustainability as improvements (Calero \& Piattini 2017; Lago et al. 2015). While disciplines vary, there appears to be a common agreement on continuity over time, implying both permanence and consistency with the same degree of efficacy. 
According to Purvis et al. (2019), the three aspects of sustainability (social, economic, and environmental), typically depicted by three intersecting circles with overall sustainability at the centre, has become widely accepted, as seen below:

Fig. 1
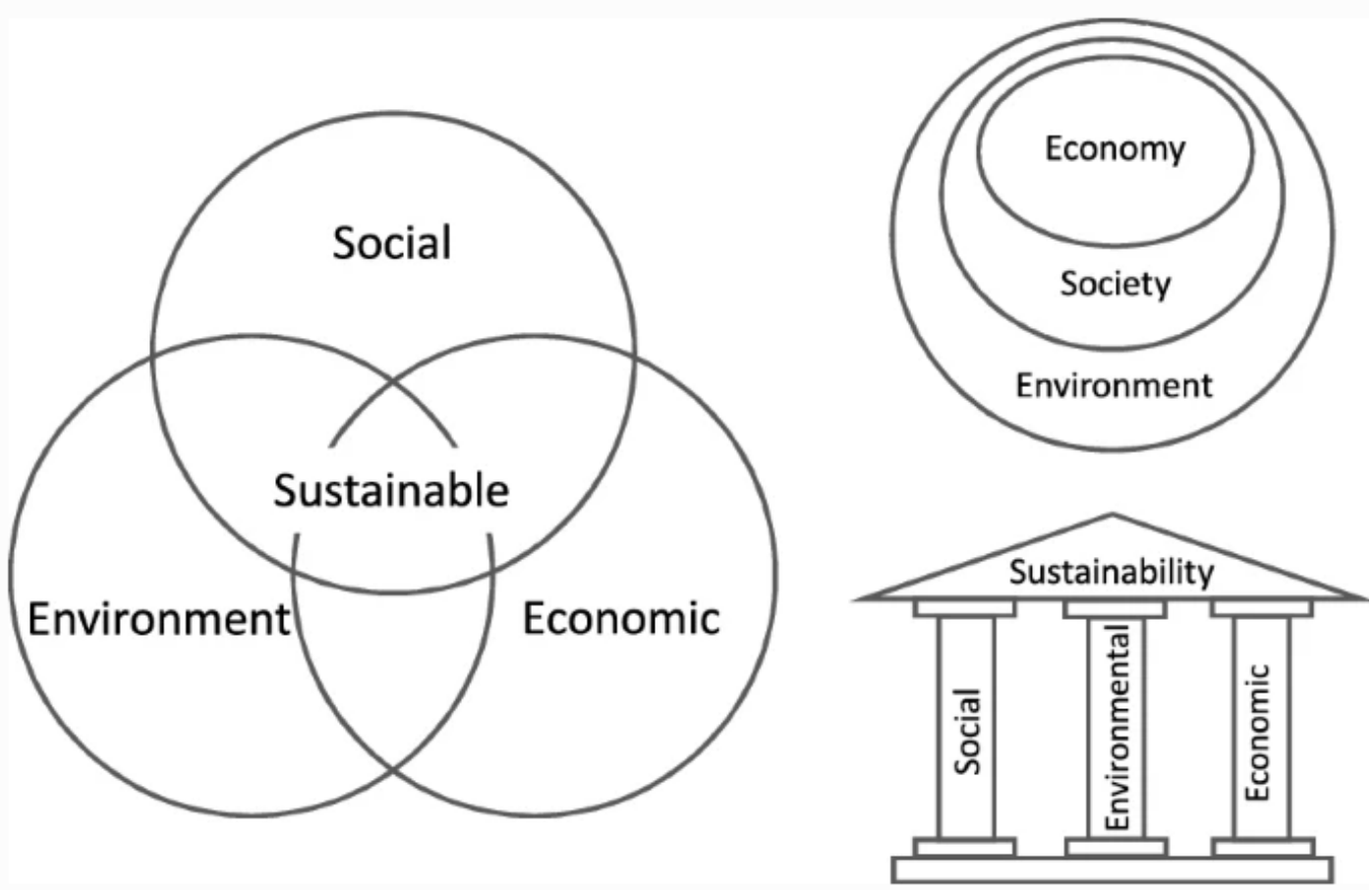

Figure 1: The three aspects of Sustainability (Purvis et al. 2019)

\subsection{Literature gap of the sustainability of E-Learning}

There is numerous research about the sustainability of E-learning in the world conducted, strikingly during Covid 19.

A study carried by Panigrahi, Srivastava \& Sharma (2018) reveals the sustainable development of online learning is dependent on successful acceptance, sustained use, and ultimately achieving the desired goals. Moreover, numerous elements influence this conclusion; for example, in different nations with distinct cultural features, his type of learning application varies. Factors such as perceived usefulness, perceived ease of use, reported enjoyment, 
duration of effort, etc. could vary from the individual to the broader level, as can external factors such as subjective standards, social standards, country culture, social network features (Panigrahi, Srivastava \& Sharma 2018).

According to Chun et al. (2012), understudies examining at a Hong Kong college were conducted and identified the compatibility of innovation and their learning styles and needs. Moreover, the accessibility of support and back from peers and instructors and their demeanours toward creation overwhelmed students for online learning. Seen convenience of innovation for learning and students' discernments of their standard ICT proficiency abilities had less prescient control on their innovation usage. The study proposes advancing students' selection of innovations for learning by upgrading their appreciation of educationist utilities learning and maximizing teachers' and peers' part in forming and supporting their innovation use.

Al-Busaidi's (2013) research found that learners' desire to study online in developing countries is dependent on learner characteristics and their use of blended learning methods. Verbert et al. (2014) found that blended learning generates the highest grade-level results when students collaborate with teacher initiative and feedback.

Additionally, in the light of rapid Internet proliferation, it has broadened the potential to learn online from mobile devices at any time and from any location. Unfortunately, the output of this learning approach may be varied among individuals. From a digital perspective, persons born and nurtured in the digital (Prensky 2001) will take longer to adjust to teaching and online learning. In some areas where poverty is still prevalent, people cannot access the Internet and learn through information technology systems such as e-learning.

Hence, it is evident that during the Covid-19 pandemic, students who lack or have limited socioeconomic resources to acquire information systems are more likely to fall behind or encounter additional problems. With the evidence given above, there are many dissenting views on the usefulness and durability of this learning method and whether it can evolve into a long-term learning trend (post-Covid-19). 
Notably, Online learning has already addressed some issues regarding sustainability. Digitization of documents and resources significantly decreases the need for printing assessment briefs, exams, module study guides, and handbooks, papers and books, lecture notes, and textbooks. This trend is observed in libraries where digitization of documents and the green Libraries" concept are prevalent (Brodie 2012; Jankowska \& Marcum 2010).

According to lonescu et al., (2020), the sustainability of e-learning is deemed practical if it fits the three criteria listed below:

- A learning model meant to give knowledge and communication techniques that could be implemented in courses and appraised as helpful for learning and teaching based on empirical evidence.

- Proven online education sources, concepts, or designs with discovering students could be modified for use far off the initial development setting.

- Maintenance, utilization, and continuous growth of the elearning concept, design, system, or materials are not contingent on a few folks who developed them to the point that future outlook would be jeopardized if their involvement was not halted.

Moreover, the study was representative of a national sector with just eight university students in Romania. The findings offer a broad view of current challenges to e-learning sustainability across the industry. The research results revealed that university students in Romania were not prepared for exclusively online learning during Covid. Thus, the advantages of online learning identified in other studies seem to diminish in value, while disadvantages become more prominent. The hierarchy of problems that arise in online learning changes in the crisis caused by the pandemic. Technical issues are the most important, followed by teachers' lack of technical skills and their teaching style improperly adapted to the online environment. However, the last place was assigned by students to the lack of interaction with teachers or poor communication with them. 
According to the study of Gunn (2016), semi-structured interviews with e-learning professionals, middle managers, and academic support personnel from six of New Zealand's eight universities and three polytechnics provided insight into their experiences. Their comments highlighted institutional as well as cultural challenges to long-term sustainability. The following sustainability influences were recognized and discussed: supporting organizational structures, a common vision, and employee accountability. The paper contends that not all efforts are long-term, and it offers practical ways for attaining diffusion and continuity through communal activity. The research finds that cross-functional cooperation is required to accommodate multiple and often opposing perspectives. The research yielded three conclusions: (1) there is no single formula for sustainability that can be compelled to complete in every situation; (2) schemes that have proven successful in different settings are available for consideration, and (3) accommodating different stakeholder views is a vital element that must be interpreted in light of specific contexts.

Regarding the research of Bell (2017), The interviews involved asking the Vice-Chancellors or Rectors of the four selected universities selected across Europe relating to the sustainability model and the likely impact of current disruptions in the future. The study shows how the university's strategy contributes to the specific international challenge of sustainable development. Furthermore, the likely futures for online learning and the country and language boundaries change to the sustainability of online learning.

The E-learning system increasingly plays a vital role in sharing and transferring knowledge, especially training institutions such as universities. Successful implementation of the E-learning system requires universities to identify the factors that influence the system's adoption from students, teachers and managers. In any case, the obstacles to the spread of practical e-learning innovations and continuity for further development and future usage have proven significant (Stiles and Yorke 2006). 
Universities, in particular, are essential factors in education for sustainable development because of their flexibility in the learning process, use of technology, and multidisciplinary approach to teaching and learning. One case study that becomes sustainable presents a model for success. However, none of the universities in Vietnam analyses successful examples or uses them to inform e-learning strategy implementation. Therefore, this research is conducted in one technology-leading university in Vietnam to be the first model for the sustainability of online learning in this country.

\section{METHODOLOGY}

\subsection{Overview research approaches}

In this study, a qualitative research method is conducted in the form of in-depth interviews.

Bhandari (2020) defines qualitative research as a type of social science research that collects and works with non-numerical data and seeks to interpret meaning from these data to help understand social life by studying targeted populations or locations. Qualitative analysis uses data to describe a phenomenon, articulate what it means, and understand it (Hancock, Windridge \& Ockleford 2007). Most types of research involve categorising verbal or behavioural data, or classification, summarization, and tabulation (Hancock, Windridge \& Ockleford, 2007).

This study uses a qualitative research method because it allows researchers to investigate the meanings people ascribe to their behaviour and interactions with others to shed light on why this association exists. It focuses on primary data extraction through a preprepared questionnaire and interviews individually online through a video call to gain relevant information to conclude the sustainability of online education among undergraduate students, lecturers and managers of FPT University in Vietnam.

In the research, carrying out interviews is the approach to obtain needed data. There are several ways to conduct an interview, such as 
by phones, computers, or in person, with the benefit of identifying verbal responses of the interviewees, thus clarifying the intended question (Ponto 2015). To pursue more detailed answers from the participants, the semi-structured interview approach is used based on a list of queries to be covered. However, the order and way of asking questions may depend on the context and characteristics of the interviewee, while ensuring the list of questions helps to identify the issues that need to be collected information while still allowing the accuracy of the questions and flexibility required to discuss emerging issues (Gill et al., 2008).

Interviews can be done either individually or in a group. While individual interviews are more helpful in elaborating on the meaning of an event, situation, or social context to each participant in a setting (Fox 2009), group interviews will help form a bigger picture about a location or incident (Morgan, 1998).

In this research, individual interviews are the chosen method.

Moreover, the answers collected in the interviews are used as primary data, which are analyzed with the qualitative analysis approach. Primary research results data are gathered for a specific research problem at hand, adopting the optimal procedure for the research problem (Hox \& Boeije, 2005).

\subsection{Research participants}

In this research, 50 participants, including 30 students, 12 lecturers, and 8 managers from Business Administrations of FPT University, are interviewed individually.

\subsection{Data collection}

Data collection was conducted for four months, from 28th February 2021 to 28th May 2021.

A group of 30 students, 12 lecturers, and 8 managers from Business Administrations of FPT University were involved in the interview sessions, which aimed to gauge their perceptions about the sustainability of E-learning in the university in Vietnam. Each interview 
took place around 30 minutes. All conversations were recorded with permission and transcribed for further analysis.

\section{FINDINGS}

\section{The probability of sustainability of E-learning}

Based on the research results, there are similarities in the perception for the high probability of sustainability of E-learning from managers, lecturers and students at $100 \%$.

Moreover, blended learning is chosen to be the best learning method for sustainability in this university by all the participants at more than $90 \%$.

Moreover, the social, environmental and economic aspects of sustainability of E-learning illustrate some common points as below:

\section{Environment aspect}

One hundred percent of lecturers, managers and students agree that E-learning leads to less traffic in the cities. All participants appreciate E-learning, especially in the scorching summer in Vietnam, due to reducing the amount of time commuting under the burning weather affecting the health and spirit of lecturers. In return, the air quality increases, and the pollution rate decreases significantly when the number of vehicles and citizens plunged.

\section{Economic aspect}

$100 \%$ of students, lecturers, and managers confirmed that online learning reduces transport and parking, eating out, and business attire. Moreover, it improves the cost-effectiveness of education since it saves time commuting to university, reduces the cost of commuting to universities and increases the productivity of daily work.

\section{Social aspects}


$100 \%$ of participants concluded that the primary factors behind using online learning are improving access to education and training and the quality of learning for every student.

- Removing the limitation of learning time and space

The time lag attributes of asynchronous learning, unlike synchronous learning in online platforms, take advantage of accessing materials anytime and anywhere, the ability to reach a greater mass at the same time, and uniformity of content. Unlimited time and space is an advantage of online learning. Online learning is also beneficial for students as they can learn at their own pace with online materials. Everybody can study at home, expand to cafes, libraries, or consider at any time of the day that they feel is appropriate.

- Empowering flexible, even customised learning platforms and courses to adapt to diverse learning styles, characteristics, foundations, and pace of students.

With innovative learning by web learning programs, students can create numerous distinctive ways to memorize, depending on each individual's learning pace and foundations. Moreover, E-learning met the differences in foundations and favoured learning styles of the student community. Students from numerous distinctive places can still enlist for a lesson together. In addition, one can select a class that fits their learning style and needs because online learning has customized the course for each student.

- Providing practical and convenient online interaction and access to the education system

With the improvement of science and innovation, numerous channels and devices have been made around online courses to assist instructors and students with email, video conferences, web-based programs, mobile applications etc. E-learning systems might provide effective and convenient access to learning materials, support 
communication platforms among instructors and learners, and enhance learning opportunities.

Due to these characteristics, all participants agreed that online learning could permit an intriguing approach to instruction and learning, constituting critical components in education for sustainability advancement.

\subsection{Perspectives from FPT University - Business Administration lecturers}

\subsubsection{The probability of sustainability of E-learning}

$100 \%$ of lecturers confirmed that the sustainability of E-learning in Vietnamese universities is a high probability.

\section{Social aspects}

$3 / 12$ of the lecturers ( $25 \%)$, who are pregnant, have small children in kindergarten and primary schools, or are single-parents with less support from other family members, prefer E-learning to traditional offline learning. Therefore, they can easily balance work and life.

\section{Economic aspects}

The salary of online teaching is the same as offline teaching during Covid; therefore, $100 \%$ of lecturers confirmed that they prefer blending learning in the future if the salary of online teaching remains the same.

\subsubsection{Challenges for sustainability}

- High workload, trouble finding assets, natural motivating forces to be imaginative, and substantial restricted rewards are everyday encounters. There is inadequate access to online games and exercises due to insufficient financing from college. These activities collectively included significant imaginative exertion and numerous hours of online applications, concept and materials improvement, and assessment. After the day, 
speculation through financing, instructing and learning awards, and bolstering administrations yielded small returns.

- Pressure on lecturers to preserve discipline-based requirements instead of focusing on instructing and studying enhancement;

- The faculty are so hustling that they cannot prioritise exploring new approaches to teaching content. There are cultural and language barriers to cross before engagement with successful initiatives developed elsewhere can occur.

- Lack of awareness or failure to utilize customer services that could contribute to initiatives.

- Maintaining enrollment and student satisfaction over time: Retaining students on such platforms is a crucial challenge with a high attrition rate as a personal touch by the instructor is missing or limited.

- Ineffective for students with low self-study: Flexibility of the learning method also requires high self-awareness of students to achieve the desired goal.

\subsubsection{The best sustainable method in the university}

$100 \%$ answered Blended learning to guarantee the quality of degree and avoid cheating in the exams. Moreover, some soft skill courses such as teamwork, group presentation, negotiation, debating, and emotional intelligence need real interaction between lecturers, students, and peers. The course's effectiveness mainly comes from real interaction between lecturers and students, and peers. Online learning, along with face-to-face learning, is successfully used in industry and academia with positive outcomes. The learning engagement, an imperative predecessor to education, is lower for technology-mediated learning than for face-to-face learning.

\subsection{Perspectives from FPT University- Business Administration managers}

\subsubsection{The probability of sustainability of E-learning}


$100 \%$ of managers confirmed that the sustainability of E-learning in Vietnamese universities is a high probability. There are some different points in economic and social aspects that are added to the research results as follows:

\section{Economic aspects}

Online learning diminishes costs related to scenes and physical learning materials: The fetching of leasing settings, printing costs of reports and other costs such as power, water, security, etc., are cut down to lower the cost of online courses.

\section{Social aspects}

The trend of advanced technologies, such as Artificial Intelligence, Blockchain, Virtual Reality, Cloud systems etc., is still booming in Vietnam, boosting E-learning development learning in the future.

\subsubsection{Challenges for sustainability}

- $\quad$ Cheating in examinations

Online contests and tests take place without direct supervision. Therefore, exam fraud is a dilemma that must be addressed in the future for the sustainability of E-learning.

\section{- Losing control of timetable of teaching}

All the managers are concerned about losing control of time and the quality of teaching in online classes. There are some issues such as late attendance of both lecturers and students, leaving the classes earlier. However, they still cheat or lie because of weak internet connection or other technical issues.

- Losing control of the quality of teaching 
The low quality of the Internet network and noisy studying space at homes of students and lecturers may lead to ineffective teaching. Moreover, cheating in the final exam combined with this challenge makes the measure of teaching quality more burdensome for managers.

\subsubsection{The best sustainable method in the university}

$100 \%$ of managers agree that blended learning is the best method. Building a blended learning environment that will be useful, agreeable, and student-centred: Rather than one class with hundreds of understudies with one speaker, with online courses, this could move to one-to-one online classes. In addition, understudies are proactively choosing for themselves the correct method, making the lesson student-centred and extending the teaching's coverage. There is no settled space and time, which suggests there is no restraint on the number of individuals considered in a lesson or course. The extent of instructing is expanded to back understudies as much as possible.

\subsection{Perspectives from FPT University- Business Administration students}

\subsubsection{The probability of sustainability of E-learning}

$100 \%$ of students confirmed that the sustainability of E-learning in Vietnamese universities is a high probability.

There are some different points in economic and social aspects that are added to the research results as follows:

\section{Economic aspects}

$100 \%$ of students require lower course fees for online learning sustainability. If the online course fee remains the same as traditional offline classes, they prefer to study offline because of more interaction and effectiveness. Currently, the online course fees in some semesters during Covid even increased or remained the same, which causes the students' dissatisfaction. 


\section{Social aspects}

$3 / 30$ of students $(10 \%)$, who have health or disease issues, shy or introverted characteristics, dwelling far away from the university, prefer E-learning to traditional offline learning. Since it is more effortless to interact online through chat or comments on video conferences or email than face-to-face communication. Moreover, they often achieve higher scores on online exams than paper ones due to less anxiety in a more comfortable learning environment at home.

\subsubsection{Challenges for the sustainability of E-learning}

- Isolated feelings arise after a long time of online learning since the interaction between the lecturers and the audience is lacklustre.

$100 \%$ of students confirmed that online instruction requires more self-discipline and a quiet online learning environment without being disturbed by family members and external factors.

- Depending heavily on external factors (stability of transmission line, communication channel, quality of headphones, microphone, etc.; software and hardware technologies must always be up to date. The stable and speedy network quality, quiet learning space, and knowledge of technology are barriers for students to access the lecture and familiarize themselves with this new learning method.

- Inferior customer service

$100 \%$ of students reviewing customer care are dissatisfied, especially in asynchronous learning. On the other hand, some studies show satisfactory respect for synchronous learning, such as many incentives, interactions between lecturers and students, and the effective email care system, which supports students well.

\subsubsection{The best sustainable method in the university}


$90 \%$ of students answered blended learning. Only three students working at the company and studying simultaneously preferred synchronous learning because it is more convenient for them to manage work and study timetables without commuting to university.

For asynchronous learning, the interaction level between lecturer and student is not high: Recorded lectures will have less interaction between lecturers and students. The students' questions are often not answered immediately, making learning difficult and interrupted.

\section{CONCLUSION}

To conclude, this investigation of organizational issues, the benefits and challenges of supporting economic e-learning activities have been illustrated. Based on the information which is gathered, Vietnam holds the potential for a thriving online learning market. Online learning has proven to positively impact FPT University and universities in Vietnam as a whole. Lecturers, students, and managers have pointed out that the sustainability of E-learning is promising. However, there are still significant challenges to overcome to be sustainable in the future because people are still sceptical about how effective online learning can be, which is but one of the many issues listed in our findings. Moreover, the author suggests some recommendations:

(1) Limiting the number of students per course. Therefore, lecturers can efficiently guide students and have time to take care of each student.

(2) Finding the balance between offline class time and online class time so students will not be overwhelmed. The best method is blended learning based on the results of the research.

(3) Diminishing the barriers to applying e-learning to become a sustainable method, advertising and arranging conferences and customer services to explain and support online learning would help lecturers and students better understand how online learning works. Moreover, a community of online peers could support learners to 
reduce attrition rates, overcome feelings of isolation, and enhance their learning interaction.

(4) Briefing, buddying, and rewards in universities in online instruction require more self-discipline and online learning regulations for students rewards on the performance are proposed to attract understudies. It is also necessary that universities in online instruction require universities' self-discipline and online learning regulations of elearning require the same conducive conditions, motivations and execution measures as any other vital initiative. E-learning activities are recognized in continuous execution, feedback research, advancement, and grantplans in universities. This initiative pursued a teaching team approach with tangible support from the head of the department. This support took the form of resource allocation, workload accounting, and recognition of teaching enhancement initiatives in performance review and promotion processes.

(5) The need for collective action is obvious. The different roles of managers, lecturers, and students towards cross-functional connections around e-learning must be defined in the policy of universities. Collaborative activity is required to make this adaptable approach more steady and maintainable than its current performance. This solution requests an exceptional degree of cross-functional collaboration to oblige diverse viewpoints.

The sustainability of E-learning has been recognized based on the research findings; however, activity to impact their evacuation remains ill-defined and subordinate to exceptional arrangements for collective action. There are still many issues that require further research with the higher number of participants from different universities in Vietnam, and assessments need to be made to evaluate the effective strategy for universities. 


\section{REFERENCES}

Alexander, S 2001, 'E-learning developments and experiences', Education + Training, vol. 43, no. 4/5, pp. 240-248: https://scihub.bban.top/https://doi.org/10.1108/00400910110399247

Al-Busaidi, K.A 2013, 'An empirical investigation is linking learners' adoption of blended learning to their intention of full e-learning', Behaviour \& Information Technology, vol. 32, no. 11, pp. 1168-1176.

https://www.tandfonline.com/doi/abs/10.1080/0144929x.2013.774047

Alharthi, A.D, Spichkova, M \& Hamilton, M 2019, 'Sustainability requirements for eLearning systems: a systematic literature review and analysis, Requirements Engineering, vol. 24, no. 4, pp. 523-543.

https://www-proquest-

com.ezproxy.lib.swin.edu.au/docview/2047952359?pq-origsite=primo

Basilaia G., Dgebuadze, M., Kantaria, M., \& Chokhonelidze, G. (2020). Replacing the classic learning form at universities as an immediate response to the COVID-19 virus infection in Georgia. International Journal for Research in Applied Science \& Engineering Technology, 8(III).

Purvis, B, Mao, Y \& Robinson,D (2019) Three pillars of sustainability: in search of conceptual origins, Sustainability Science, volume 14,681-695

Bell, S, Douce, C, Caeiro, S, Teixeira, A, Martín-Aranda, R \& Otto, D 2017, Sustainability and distance learning: a diverse European experience? Open Learning: The Journal of Open, Distance and eLearning, volume 32, 95-102

Brodie, M 2012, 'Building the sustainable library at Macquarie university, Australian Academic \& Research Libraries, vol. 43, pp. 416.

https://www.researchgate.net/publication/271746972 Building the S ustainable Library at Macquarie University 
Bhandari, P 2020, An introduction to Qualitative research, Scribbr, viewed

$<$ https://www.scribbr.com/methodology/qualitative-research/>.

Calero, C \& Piattini, M 2017, 'Puzzling out software sustainability', Sustainable Computing: Informatics and Systems, vol. 16, pp. 117124.

https://alarcos.esi.uclm.es/DocumentosWeb/2017-

Sustainable\%20Computing-Calero.pdf

Chun, L, Wang, Q \& Jing, L (2012), What factors predict undergraduate students' use of technology for learning? A case from Hong Kong, Computers \& Education, volume 59(2), 569-579

Dan, T 2019, Online education promotes Vietnam's digital economy, VnExpress, viewed 15 June 2021, <https://vnexpress.net/giao-ductruc-tuyen-thuc-day-nen-kinh-te-so-viet-nam-3931721.html>.

Hocmai 2020, Hocmai. vn - Common school of Vietnamese students, Hocmai, viewed 15 June 2021, $<$ https://hocmai.vn/mod/resource/view.php?id=32440>.

Le, V 2019, Foreign capital poured into education, VnExpress, viewed 15 June 2021, <https://vnexpress.net/von-ngoai-do-vao-giao-duc4015488.html>.

Dan, T 2020, Online Study Advantages, VnExpress, viewed 15 June 2021, <https://vnexpress.net/diem-cong-cua-hoc-truc-tuyen4070418.html>.

Fox, N 2009, 'Using interviews in a research project', National Institute for Health Research.

Gill, P, Stewart, K, Treasure, E \& Chadwick, B 2008, 'Methods of data collection in qualitative research: interviews and focus groups', British Dental Journal, vol. 204, pp. 291-295. https://www.nature.com/articles/bdj.2008.192\#author-information

Gunn, C 2016, Sustainability factors for e-learning initiatives, Research in Learning Technology, Volume 18 - Issue 2 
Hox, J.J \& Boeije, H.R 2005, Data collection, Primary versus Secondary. In K. Kempf-Leonard (ed.), Encyclopedia of Social Measurement, San Diego, CA: Academic Press, pp. 593 - 599.

Hancock, B, Windridge, K \& Ockleford, E 2007, 'An introduction to Qualitative research', The NIHR Research Design Service for the East Midlands.

Ionescu,A, Paschia, L, Nicolau, L , learningthe the tanescu, S, Stancescu, V, Coman, M \& Uzlau, M 2020, Sustainability Analysis of the E-Learning Education System during Pandemic Period-COVID19 in Romania, MDPI Sustainability

Jankowska, M.A \& Marcum, J.W 2010, 'Sustainability challenge for academic libraries: planning for the future, College and Research Libraries, vol. 71, pp. 160-170.

https://www.researchgate.net/publication/283144976 Sustainability Challenge for Academic Libraries Planning for the Future

Kim, K.J \& Bonk, C.J 2006, 'The future of online teaching and learning in higher education: the survey says...', EDUCAUSE QUARTERLY, pp. 22-30.

https://faculty.weber.edu/eamsel/Research\%20Groups/Online\%20Learning/Bonk\%20(2006).pdf

Lago, P, Koçak, S.A, Crnkovic, I \& Penzenstadler, B 2015, 'Framing sustainability as a property of software quality', Communication of the ACM, vol. 58 , no. 10 , pp. $70-78$.

https://www.researchgate.net/publication/282325166 Framing Susta inability as a Property of Software Quality

Littlefield J. (2018). The difference between synchronous and asynchronous distance learning https://www.thoughtco.com/synchronous-distance-learningasynchronous-distance-learning-1097959 
Liyanagunawardena, T.R, Lundqvist, K.O, \& Williams, S.A 2015, 'Massive open online courses and economic sustainability', European Journal of Open, Distance and E-Learning, vol. 18, no. 2, pp. 95-111. https://scihub.bban.top/10.1515/eurodl-2015-0015

Marshall, B, Cardon, P, Poddar, A \& Fontenot, R 2013, 'Does sample size matter in qualitative research?: a review of Qualitative interviews in IS research', The Journal of computer information systems, vol. 54, no. 1 , pp. 11-22

\section{https://www-proquest-}

com.ezproxy.lib.swin.edu.au/docview/1471047612?pq-origsite=primo

McBrien J. L., Cheng R., Jones P. (2009). Virtual spaces: Employing a synchronous online classroom to facilitate student engagement in online learning. The International Review of Research in Open and Distributed Learning, 10(3), 1-17. [Google Scholar]

Morgan, D.L 1998, The Focus Group Guidebook, SAGE Publications, Inc., London.

Panigrahi, R, Srivastava, P.R \& Sharma, D 2018, 'Online learning: adoption, continuance and learning outcome - a review of the literature, International Journal of Information Management, vol. 43, pp. 1-14.

https://www-sciencedirectcom.ezproxy.lib.swin.edu.au/science/article/pii/S0268401216304662

Ponto, J 2015, 'Understanding and evaluating survey research', Journal of the Advanced Practitioner in Oncology, vol. 6, pp. 168-171.

Prensky, M 2001, 'Digital natives, digital centredevelopment learningboosting immigrants part 2: do they really think differently?', On the Horizon, vol. 9 no. 6, pp. 1-6.

https://www.emerald.com/insight/content/doi/10.1108/107481201104 24843/full/html

Rennie, F \& Morrison, T 2013, E-learning and social networking handbook: resources for higher education, 
2ndresearchsustainabilityand Markets 2018, Research and markets global earning management system (LMS) market analysis and forecasts 2017-2025 - the need for LMS in HEO driving market growth.

Stepanyan, K, Littlejohn, A \& Margaryan, 2010, 'Sustainable elearning in a changing landscape: a scoping study (SeLScope)', UK Higher Education Academy.

Verbert, K, Govaerts, S, Duval, E, Santos, J.L, Assche, F.A, Parra, G \& Klerkx, J 2014, 'Learning dashboards: an overview and future research opportunities', Personal Ubiquitous Computing, vol. 18, pp, 1499-1514.

https://link.springer.com/article/10.1007\%2Fs00779-013-0751-2

Vietnamnews 2021, E-learning methods see boom during COVID-19 pandemic

https://vietnamnews.vn/economy/715821/e-learning-methods-seeboom-during-covid-19-pandemic.html

Zhan, Z, Fong, P.S, Mei, H, Chang, X, Liang, T \& Ma, Z 2015, 'Sustainability education in massive open online courses: a content analysis approach', Sustainability, vol. 7, pp. 2274-2300. https://scihub.bban.top/https://doi.org/10.3390/su7032274 